\title{
Tuberculin purified protein derivative and cryotherapy in the treatment of genital warts: A randomized controlled trial
}

\author{
Original \\ Article \\ Alaa El-Din A. Moubasher, Mena R. Kolta, Hisham D.Gaber \\ Dermatology, Venereology and Andrology, Faculty of Medicine, Assiut, Assiut University, \\ Egypt
}

\begin{abstract}
Background: Therapeutic modalities for genital warts are mostly ablative in nature, limited by high recurrence rates and are unsuitable for numerous lesions. Immunotherapy has the potential to overcome these limitations.

Aim: The aim of this work was to compare the results of combined tuberculin purified protein derivative and cryotherapy to the results of tuberculin purified protein derivative or cryotherapy alone in the treatment of genital warts.

Patients and Methods: A randomized controlled study included 45 patients equally allocated into three groups using a computerized random number: Group A (15) patients were treated with purified protein derivative injection. Group B (15) patients were treated with cryotherapy using liquid nitrogen. Group C (15) patients were treated with combined purified protein derivative and cryotherapy.

Results: In group A, 2 patients (13.3\%) had complete response to purified protein derivative therapy, 8 patients $(53.3 \%)$ had partial response, and 5 patients $(33.3 \%)$ no response to treatment. While in group B, 4 patients $(26.7 \%)$ had complete response to cryotherapy, 6 patients $(40 \%)$ partial response, and 5 patients $(33.3 \%)$ no response to treatment,in group C 7 patients $(46.7 \%)$ complete response 6 patients $(40 \%)$ partial response, and 2 patients $(13.3 \%)$ no response, with no statistical significant difference.

Conclusion: Intralesional immunotherapy with purified protein derivative effectively cures warts that are present locally and also at distant sites. It is safe, economic, and efficacious. Combined purified protein derivative and cryotherapy was found to be the most effective treatment modality for genital warts.
\end{abstract}

Key Words: Cryotherapy, immunotherapy, viral warts.

Received: 09 February 2021, Accepted: 05 April 2021.

Corresponding Author: Hisham D. Gaber, Department of Dermatology, Venereology and Andrology, Faculty of Medicine, Assiut University, Egypt, Tel.: +2088-2340680, E-mail: hishamdiabg@yahoo.com

ISSN: 2090-6048, 2021

\section{INTRODUCTION}

Common warts or verruca vulgaris are hyperkeratotic papillomas caused by infection with human papilloma virus (HPV), which is a double-stranded DNA virus and most commonly located on the skin and genitalia ${ }^{[1]}$. Over 118 types of HPVs have been identified and more than 35 types infect the genital tract ${ }^{[2]}$. Types 6 and 11 HPVs are associated with low-risk anogenital warts and types 16,18,31,45, and 59 are most commonly associated with squamous cell and adenocarcinomas of the cervix ${ }^{[3]}$. As regards skin warts, they are frequently seen on the hands of children and young adults ${ }^{[4]}$, whereas anogenital warts (venereal or condylomaacuminata) occur in perineum and on the genitalia or in the genital tract and are considered one of the most common sexually transmitted diseases (STDs) $)^{[5]}$. Many observations have suggested that wart proliferation is controlled by the immune system, particularly the cell-mediated immunity ${ }^{[6]}$. Intralesional immunotherapy by different antigens has been proved effective in the treatment of different types of warts $^{[7]}$. Intralesional immunotherapy employs the ability of the immune system to recognize certain viral, bacterial, and fungal antigens that induce a delayed-type hypersensitivity reaction, not only to the antigen but also against the wart virus, which, in turn, increases the ability of the immune system to recognize and clear $\mathrm{HPV}^{[8]}$. Immunotherapy appears to enhance recognition of the virus by the immune system: this allows clearance of the treated wart and frequently warts at distant sites and helps to prevent future clinical infection through induction of a long-term immunity to HPV ${ }^{[9]}$. Cryotherapy is widely used as an accepted mode of treatment with relative safety and moderate discomfort for patients ${ }^{[10]}$. Tissue destruction occurs as a result of rapid heat transfer from the tissue causing tissue injury, vascular stasis, occlusion, and inflammation ${ }^{[1]}$. 


\section{PATIENTS AND METHODS}

This study is a randomized controlled trial. This study was carried out in the Dermatology and Andrology Outpatient Clinic, Assiut University Hospitals from June 2018 till December 2020. The cases werediagnosed by trained well-qualified dermatologists and andrologists. Cases having lesions with diameter of equal to or more than $10 \mathrm{~mm}$, which located on the pubis, penis, scrotum, anal or inguinal area and number of 5 or more genital or anal warts were included. Cases with vaginal and cervical lesions, history of immunosuppressive status, history of immune modulator drugs use that were administered in the past 4 weeks, history of local antiviral agents use in the past 2 weeks, pregnancy, breastfeeding, destructive therapies, and the presence of any other concomitant STD were excluded. The study has been approved by the institutional review board: IRB No. 17100077. Privacy and confidentiality of all data were assured.

\section{Sampling method}

\section{Systematic random sample method}

Randomization: A total of 45 patients who enrolled in the study were equally allocated into three groups using a computerized random number: Group A (15) patients were treated with purified protein derivative (PPD) injection. Group B (15) patients were treated with cryotherapy using liquid nitrogen. Group C (15) patients were treated with combined PPD and cryotherapy

Data collection tools: Consent was signed by each patient and control before enrollment into the study.

(1) Full medical history taking: A medical history was performed for all patients, including

(2) Local dermatological examination: The whole body was inspected in good day light for the site and number of the warts, anatomical distribution of the warts all over the body, type of the warts, and complete dermatological examination for the presence of any other skin problems.

\section{(3) Intervention}

\section{Cryotherapy group}

Cryotherapy was performed using liquid nitrogen, at a temperature of $196^{\circ} \mathrm{C}$, with cryogun. Pre-treatment photographs were taken. We used Timed Spot Freeze Technique; this method involves spraying of cryogen from a hand held gun device that holds about $300 \mathrm{ml}$ of liquid nitrogen. Cryotherapy with liquid nitrogen spray was applied perpendicularly to wart at a distance of about $2 \mathrm{~cm}$. The lesion was sprayed until the ice-ball formed with at least a 2-mm margin of the lesion. The time of spraying was proportional to the treated area (20-30s). The employed regimen included 3 complete cycles of freezing followed by 10 s thawing. Scales were removed gently with a sterile blade before cryogen application, if needed. Cryotherapy was also performed every other week for four consecutive treatments. Post treatment photographs were taken, and any adverse reactions were noted down. We kept the patients on analgesics and topical mupirocin cream for 5 days after the procedure.

\section{Tuberculin PPD group}

The volume of PPD antigen for intralesional injection was determined by the size of the test reaction in each patient following the method described by Johnson et al. ${ }^{[12]}$ : Injections were made using similar insulin syringes held parallel with the skin surface with the bevel facing upward. Response and adverse events (if any) were documented at each session of treatment. Depending on the decrease in lesion size, the response was categorized as good (no visible lesion), intermediate (50-99\% improvement) and poor (less than 50\% improvement).

The severity of pain was assessed by the visual analogue scale 8 (VAS score): 0 for no pain and 10 for the maximum pain. The first endpoint was to assess the change in the size of the lesions after 2 weeks of intervention.

\section{Operational design}

The researcher introduced himself to all participants included in this study and asked them to participate after illustrating the goal of the study. All selected participants received comprehensive information regarding the nature of the study, objective, and the expected benefit of the study. All ethical considerations were taken throughout the whole work. Informed consent was taken from all participants in the study.

\section{Statistical analysis}

The data were coded, entered, and analyzed by SPSS program version 14 ((Statistical Package for Social Sciences) IBM SPSS software package version 20.0. (Armonk, New York USA : IBM Crop); data were summarized as mean \pm standard deviation and percentage. $\mathrm{T}$ test was used for comparison of mean of the two groups, Chi square was used for comparison of qualitative data. Pearson's correlation test was used to test relation between two numeric variables.

\section{RESULTS}

Disease duration was from 2 to 6 months in group A with mean $3.67 \pm 1.18$ and $2-5$ months in group B with mean $3.47 \pm 0.99$ and $2-10$ months in group $C$ with mean $5.87 \pm 2.33$.

According to site of warts in group A, 7 patients were with penile warts, 4 patients were with scrotal warts, and 4 patients were with anal warts; in group B, 11 patients were with penile warts 4 patients were with scrotal warts, and in group C, 9 patients were with penile warts, 4 patients were with scrotal warts and 2 patients were with anal warts, with no statistical significant difference.

In group A, 2 patients (13.3\%) had complete response to PPD therapy, 8 patients $(53.3 \%)$ had partial response, and 
5 patients $(33.3 \%)$ no response to treatment; in group B, 4 patients $(26.7 \%)$ had complete response to cryotherapy, 6 patients $(40 \%)$ partial response, and 5 patients $(33.3 \%)$ no response to treatment; in group C, 7 patients (46.7\%) had complete response, 6 patients $(40 \%)$ partial response and 2 patients $(13.3 \%)$ no response, with no statistical significant difference (Table 1). In group A, 2 patients $(13.3 \%)$ were very satisfied about treatment response, 4 patients $(26.7 \%)$ were satisfied, 5 patients $(33.3 \%)$ were slightly satisfied, and 4 patients (26.7\%) were unsatisfied. In group B, 5 patients $(33.3 \%)$ were very satisfied about treatment response, 3 patients $(20 \%)$ were satisfied, 2 patients $(13.3 \%)$ were slightly satisfied, and 5 patients $(33.3 \%)$ were unsatisfied. In group C, 6 patients (40\%), were very satisfied, 2 patients $(13.3 \%)$ were satisfied, 4 patients $(26.7 \%)$ slightly satisfied, and 3 patients $(20 \%)$ unsatisfied. There was no statistically significant difference in patient satisfaction between the three groups (Table 2).

Table 1: Relation between disease outcome and type of therapy.

\begin{tabular}{|c|c|c|c|c|c|c|c|}
\hline Outcome & $\begin{array}{l}\text { PPD only }(\mathrm{n}=15), \\
\text { No. }(\%)\end{array}$ & $\begin{array}{c}\text { Cryo only }(\mathrm{n}=15), \\
\text { No. }(\%)\end{array}$ & $\begin{array}{c}\text { Combined }(\mathrm{n}=15), \\
\text { No. }(\%)\end{array}$ & $P$ value $^{\mathrm{a}}$ & $P$ value $^{\mathrm{b}}$ & $P$ value & $P$ value $^{\mathrm{d}}$ \\
\hline Complete improvement & $2(13.3 \%)$ & $4(26.7 \%)$ & $7(46.7 \%)$ & & & & \\
\hline Partial improvement & $8(53.3 \%$ & $6(40.0 \%)$ & $6(40.0 \%)$ & 0.306 & 0.621 & 0.114 & 0.349 \\
\hline No improvement & $5(33.3 \%)$ & $5(33.3 \%)$ & $2(13.3 \%)$ & & & & \\
\hline
\end{tabular}

PPD, purified protein derivative.

Table 2: Relation betweenpatient satisfaction and type of therapy

\begin{tabular}{|c|c|c|c|c|c|c|c|}
\hline Satisfaction & $\begin{array}{c}\text { PPD only }(\mathrm{n}=15), \\
\text { No. }(\%)\end{array}$ & $\begin{array}{c}\text { Cryo only }(\mathrm{n}=15), \\
\text { No. }(\%)\end{array}$ & $\begin{array}{c}\text { Combined }(\mathrm{n}=15), \\
\text { No. }(\%)\end{array}$ & $\mathrm{P}_{\text {value }}{ }^{\mathrm{a}}$ & $P$ value ${ }^{b}$ & $\mathrm{P}_{\text {value }}{ }^{\mathrm{c}}$ & $P$ value \\
\hline Very satisfied & $2(13.3 \%)$ & $5(33.3 \%)$ & $6(40.0 \%)$ & & & & \\
\hline Satisfied & $4(26.7 \%)$ & $3(20.0 \%)$ & $2(13.3 \%)$ & 0.306 & 0.621 & 0.114 & 0.349 \\
\hline Slightly & $5(33.3 \%)$ & $2(13.3 \%)$ & $4(26.7 \%)$ & & & & \\
\hline Dissatisfied & $4(26.7 \%)$ & $5(33.3 \%)$ & $3(20.0 \%)$ & & & & \\
\hline
\end{tabular}

PPD, purified protein derivative.

Patients with complete or partial improvement in urban areas were $26(78.8 \%)$ and $7(21.2 \%)$ in rural areas, while patients with no improvement were $7(58.3 \%)$ in urban areas and $5(41.7 \%)$ in rural areas, with no statistical significance between the two groups. In patients with complete or partial improvement, their disease duration ranged from 2 to 9 months with mean $4.21 \pm 1.93$. Patients with no improvement ranged from 3 to 10 months with mean $4.67 \pm 1.92$ with no statistical significance between the two groups. The number of patients with complete or partial improvement with penile warts were $23(69.7 \%)$, scrotal warts $8(24.2 \%)$, and anal warts $2(6.1 \%)$, while the number of patients with no improvement were 4 with penile warts $(33.3 \%), 4$ with scrotal warts $(33.3 \%)$, and 4 with anal warts $(33.3 \%)$, with statistical significant difference $P=0.028^{*}$ (Fig. 1). 


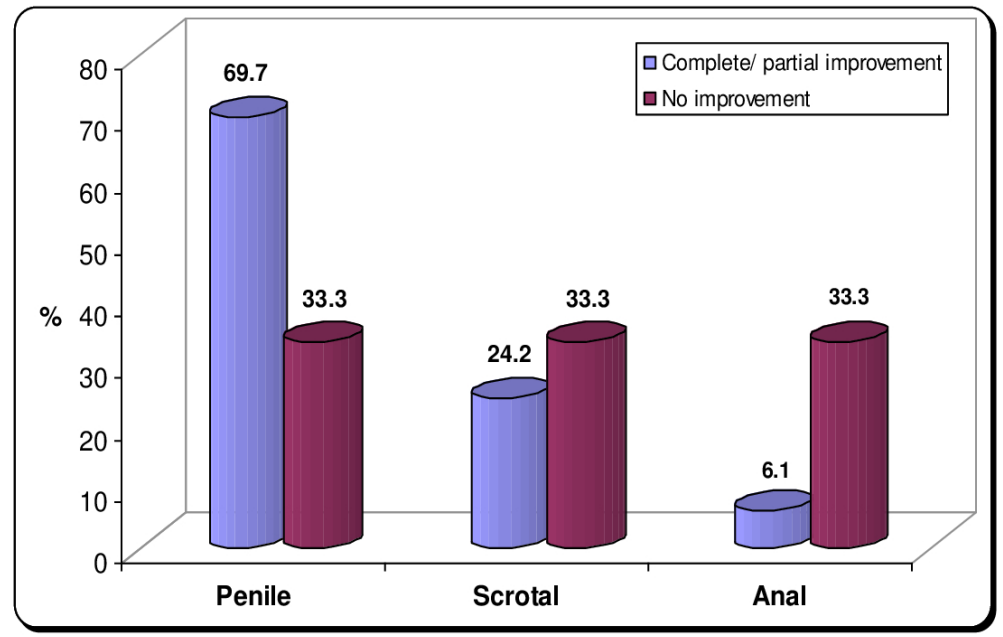

Fig. 1: Relation between outcome and characters of warts.

\section{DISCUSSION}

Immune system plays an essential role in the spontaneous resolution of warts. The stimulation of immune response would subsequently destroy all warts on the body, rather than the locally treated lesion ${ }^{[13]}$. Treatment of warts is difficult for both patients and physician as well. No single therapy has been proven effective at achieving complete remission in every patient ; as a result, many different approaches exist ${ }^{[14]}$. The present study was carried out on 45 patients with multiple genital and anal warts. The patients were divided into three groups. Group A (15 patients) were treated with PPD injection, group B (15 patients) were treated with cryotherapy using liquid nitrogen, and group C (15) patients were treated with combined PPD injection and cryotherapy. In group A (PPD), our results showed that $13.3 \%$ of patients had complete response, while $53.3 \%$ of patients had partial response and $33.3 \%$ of patients had no response to treatment. Similar studies showed variable results as Eassa et al. ${ }^{[15]}$, study, which was performed on 40 patients aged 20-35 years and presented with anogenital warts. Patients received intralesional PPD injection, and results showed complete response in $9(47.5 \%)$, partial response in $15(37.5 \%)$, and no response in $3(7.5 \%)$ of the patients. Other study was by Nofal et al. ${ }^{[16]}$, which was performed on 64 patients with genital warts, The largest wart was directly injected with intralesional tuberculin and results showed complete response in $9(32.1 \%)$ of tuberculin group patients. The exact mechanism of the clearance of warts with tuberculin PPD is not known. Its injection into the HPV-infected tissue probably generates strong pro-inflammatory signals and attracts antigenpresenting cells, which also recognize and process lowprofile HPV particles in the infected tissue. This leads to a strong adaptive immune response not only against Mycobacterium tuberculosis but also against HPV ${ }^{[17]}$.
Immunotherapy induces a delayed-type hypersensitivity reaction that increases the ability of the immune system to recognize and clear HPV. The regression of warts at distant sites had not been established with other therapies ${ }^{[12]}$.The trauma of the injection itself can also cause wart clearance in previously sensitized individuals ${ }^{[18]}$.

The clearance of untreated distant warts strongly indicated the development of a widespread cell-mediated immunity against HPV as a response to intralesional antigen injection, and it represents the main advantage of the intralesional immunotherapy ${ }^{[19]}$.

Moreover, results obtained by Amirnia et al. ${ }^{[20]}$ study was performed on 69 patients with genital warts of which $77.1 \%$ of patients showed good response to PPD injections and $18.2 \%$ of patients showed good response to cryotherapy. The better results in the PPD group in this study may be obvious due to larger sample size of the study. In patients treated with PPD injection, we recorded pain in 7 patients $(46.7 \%)$, flu-like symptoms in 3 patients (20\%), erythema in 3 patients $(20 \%)$, while in Saoji et al. (2016) ${ }^{[21]}$ study, side effects recorded were mild redness and swelling at the injection site in 3 patients $(7.9 \%)$ and flu-like symptoms as low-grade fever and body ache in 1 patient $(0.6 \%)$.

In group B (cryotherapy), our results showed that $26.7 \%$ of patients had complete response, $40 \%$ had partial response, and $33.3 \%$ had no response to treatment. However, results obtained by Jahic ${ }^{[21]}$ study was performed on 50 patients with genital wart, of which $78 \%$ of patients showed complete response while $18 \%$ of patients showed no response.

Another study, by Mohanlal et al. ${ }^{[22]}$, was performed on 40 patients with genital warts of which 20 patients were 
under treatment with cryotherapy (6 sessions), $78.9 \%$ of patients showed complete response and $21.1 \%$ of patients showed no response. The better results may be attributed to more number of sessions. Also, Camargo et al..$^{[23]}$, study was performed on 48 patients with genital warts of which 24 patients were under treatment with cryotherapy, of which $50 \%$ of cryotherapy-treated patients were completely wart free without erosions.In cryotherapy patients, we recorded pain in 5 patients $(33.3 \%)$, erosions in 3 patients $(20 \%)$, and hypopigmentation in 8 patients $(53.3 \%)$. In Jahic ${ }^{[21]}$ study, side effects of cryotherapy were exudation in $78 \%$ of patients, swelling in $72 \%$ of patients, and pain in $66 \%$ of patients. In Camargo et al. ${ }^{[23]}$, study, side effects of cryotherapy were superficial erosions reported in $37.5 \%$ of patients, mild-to-moderate pain in $100 \%$ of patients, and hypopigmentation in $45.8 \%$ of patients.

In group C (combined PPD and cryotherapy patients), our results showed that $46.7 \%$ complete response, $40 \%$ partial response, and $13.3 \%$ no response to treatment.

This is in accordance with study byAttwa et al. ${ }^{[24]}$, who reported that the cryoimmuno-therapy group resulted in $(40 \%)$ complete clearance of lesions, which was significantly superior to immunotherapy monotherapy clearance rate $(20 \%)$.

In group C (combined PPD and cryotherapy patients), we recorded pain in 10 patients $(66.7 \%)$, flu-like symptoms in 1 patient (6.7\%), erythema in 4 patients $(26.7 \%)$, and hypopigmentation in 7 patients $(46.7 \%)$.

\section{CONCLUSION}

Intralesional immunotherapy with PPD effectively cures warts that are present locally and also at distant sites. It is safe, economic, and efficacious. Combined PPD and cryotherapy was found to be the most effective treatment modality for genital warts followed by intralesional immunotherapy with PPD than that of cryotherapy.

\section{CONFLICT OF INTEREST}

There are no conflicts of interest.

\section{REFERENCES}

1. Rivera A, Tyring S K. Therapy of cutaneous human papillomavirus infections. Dermatol Ther2004; $17: 441-448$

2. De Villiers E M. Classification of papillomaviruses. J Virol2004; 324:17-27.

3. Brotzman G L. Evaluating the impact of HPVrelated diseases: cervical cancer and genital warts. J Fam Pract2005; 54(7 Suppl):S3-S9.

4. Lipke M M. An armamentarium of wart treatments.
Clin Med Res2006; 4:273-293.

5. Rintala M A, Grenman S E, Jarvenkyla M E, Syrjanen K J, Syrjanen S M. High-risk types of human papillomavirus (HPV) DNA in oral and genital mucosa of infants during their first 3 years of life: experience from the Finnish HPV Family Study. Clin Infect Dis2005; 41:1728-1733.

6. Goncalves M A, Donadi E A. Immune cellular response to HPV: current concepts. Braz J Infect Dis2004; 8:1-9.

7. Gupta S, Malhotra A K, Verma K K, SharmaV $\mathrm{K}$. Intralesional immunotherapy with killed Mycobacterium w vaccine for the treatment of anogenital warts: an open label pilot study. J Eur Acad Dermatol Venereol2008; 22:1089-1093.

8. Maronn M, Salm C, Lyon V, Galbraith S. One-year experience with Candida antigen immunotherapy for warts and molluscum. Pediatr Dermatol2008; 25:189-192.

9. Chaoi M H, Seo S H, Kim I H, Son S W. Comparative study on the sustained efficacy of diphencyprone immunotherapy versus cryotherapy in viral warts. Pediatr Dermatol 2008; 25:398-399.

10. Campbell M A. Non-genital warts: a review of current treatments. Pract Dermatol 2010; 7:42-48.

11. SharmaV K, Khandpur S. Guidelines for cryotherapy. Indian J Dermatol Venereol Leprol2009; 75:90.

12. Clifton $\mathrm{M} \mathrm{M}$, Johnson $\mathrm{S} \mathrm{M}$, Roberson $\mathrm{P} \mathrm{K}$. Immunotherapy for recalcitrant warts in children using intralesional mumps or Candida antigens. Pediatr Dermatol2003; 20:268-271.

13. Phillips R C, Ruhl T S, Pfenniger J L, Garber M R. Treatment of warts with Candida antigen injection. Arch Dermatol 2000; 136:1274-1275.

14. Sterling J C, Handfield-Jones S, Hudson P M. British Association of Dermatologists. Guidelines for the management of cutaneous warts. $\mathrm{Br} \mathrm{J}$ Dermatol2001; 144:4-11.

15. Eassa B I, Abou-Bakr A A, El-Khalawany M A. Intradermal injection of PPD as a novel approach of immunotherapy in anogenital warts in pregnant women. Dermatol Ther2011; 24:137-143.

16. Nofal A, Albalat W, Ismail A, Khattab F M. Immunotherapeutic modalities for the treatment of recalcitrant plantar warts: a comparative study. J Dermatol Treat2020; 7:1-6.

17. Elela I M, Elshahid A R, Mosbeh A S. Intradermal vs intralesional purified protein derivatives in treatment of warts. Golf J Deramatol Venereol2011; 18:21-26.

18. Kus S, Ergun T, Gun D, Akin O. Intralesional 
tuberculin for treatment of refractory warts. J Eur Acad Dermatol Venereol2005; 19:515-516.

19. Mohamad N S, Badran F, Yakout E. Evaluation of the efficacy of a combination-measles, mumps and rubella vaccine in the treatment of plantar warts. Our Dermatol Online2013; 4:463-467.

20. Amirnia S, Ray M B, Margaritis A. Copper ion removal by Acer saccharum leaves in a regenerable continuous-flow column. Chem Eng J 2016; 287:755-764.

21. Saoji V, Lade NR, Gadegone R, Bhat A. Immunotherapy using purified protein derivative in the treatment of warts: An open uncontrolled trial. Indian Journal of Dermatology, Venereology, and Leprology. 2016 Jan 1;82(1):42.
22. Jahic M Cryotherapy of genital warts. Mater Sociomed 2019; 31:212.

23. Mohanlal B, Malini P, Prasad N J, Arun R K, Kumar B P. Imiquimod vs cryotherapy in the treatment of genital warts: a comparative study. FIJCMR2018; 5:5-10.

24. Camargo C L, Belda Junior W, Fagundes L J, Romiti R. A prospective, open, comparative study of $5 \%$ potassium hydroxide solution versus cryotherapy in the treatment of genital warts in men. An Bras Dermatol2014; 89:236-240.

25. Attwa E, Elawady R, Salah E. 'Cryo-immunotherapy'is superior to intralesional Candida antigen monotherapy in the treatment of multiple common warts. J Dermatol Treat2020; 31:1-8. 